Original Article

\title{
Decrease of glycogen synthase kinase $3 \beta$ phosphorylation in the rat nucleus accumbens shell is necessary for amphetamine- induced conditioned locomotor activity
}

\author{
Joong-Keun Shin ${ }^{1, \#, \dagger}$, Wha Young Kim ${ }^{1, \#}$, Haeun Rim $^{2}$, and Jeong-Hoon Kim ${ }^{1, *}$ \\ Departments of ${ }^{1}$ Physiology and ${ }^{2}$ Medical Sciences, Yonsei University College of Medicine, Seoul 03722, Korea
}

\author{
ARTICLE INFO \\ Received November 23, 2021 \\ Revised December 8, 2021 \\ Accepted December 8, 2021 \\ *Correspondence \\ Jeong-Hoon Kim \\ E-mail: jkim1@yuhs.ac
}

Key Words

Amphetamine

Classical conditioning

GSK3beta

Lithium chloride

Nucleus accumbens

"These authors contributed equally to this work.

${ }^{+}$Current address: ILC Dover, 1003 Bukit

Merah Central, Singapore 159836
ABSTRACT Phosphorylation levels of glycogen synthase kinase $3 \beta$ (GSK3 $\beta$ ) negatively correlated with psychomotor stimulant-induced locomotor activity. Locomotor sensitization induced by psychomotor stimulants was previously shown to selectively accompany the decrease of GSK3 $\beta$ phosphorylation in the nucleus accumbens (NAcc) core, suggesting that intact GSK3 $\beta$ activity in this region is necessary for psychomotor stimulants to produce locomotor sensitization. Similarly, GSK3 $\beta$ in the NAcc was also implicated in mediating the conditioned effects formed by the associations of psychomotor stimulants. However, it remains undetermined whether GSK3 $\beta$ plays a differential role in the two sub-regions (core and shell) of the NAcc in the expression of drug-conditioned behaviors. In the present study, we found that GSK3 $\beta$ phosphorylation was significantly lower in the NAcc shell obtained from rats expressing amphetamine (AMPH)-induced conditioned locomotor activity. Further, we demonstrated that these effects were normalized by treatment with lithium chloride, a GSK3 $\beta$ inhibitor. These results suggest that the behavior produced by AMPH itself and a conditioned behavior formed by associations with AMPH are differentially mediated by the two sub-regions of the NAcc.

\section{INTRODUCTION}

Psychomotor stimulants produce rewarding and locomotor activating effects by increasing dopaminergic neurotransmission in the nucleus accumbens (NAcc) [1-4]. In addition to classic signaling pathways that use cAMP, dopamine is also known to have a distinct signaling pathway involving glycogen synthase kinase $3 \beta$ (GSK3 $\beta$ ) [5,6], a serine/threonine kinase highly expressed in the brain [7]. GSK3 $\beta$ is inhibited by phosphorylation at serine- 9 residue $[8,9]$, and there is a negative correlation between its phosphorylation levels and dopamine- and psychomotor stimulantinduced locomotor activities $[5,6]$. For example, it was shown that an increase in GSK3 $\beta$ phosphorylation attenuated the expression of locomotor sensitization induced by psychomotor stimulants, including cocaine, amphetamine (AMPH), and meth-AMPH [10-13], whereas a decrease in GSK3 $\beta$ phosphorylation enhanced the increase in locomotor activity induced by acute cocaine administration [14]. Interestingly, the expression of locomotor sensitization induced by psychomotor stimulants selectively accompanied the decrease in GSK3 $\beta$ phosphorylation in the NAcc core $[11,12,14]$, in two distinct sub-regions of the NAcc (the core and the shell) [15-17], suggesting that increased GSK3 $\beta$ activity in this region is necessary for psychomotor stimulants to produce locomotor sensitization.

In addition to sensitization, another important feature of drugs of abuse contributing to the development of craving and (i) (s) This is an Open Access article distributed under the terms of the Creative Commons Attribution Non-Commercial License, which permits unrestricted non-commercial use, distribution, and reproduction in any medium, provided the original work is properly cited. Copyright $\odot$ Korean J Physiol Pharmacol, pISSN 1226-4512, elSSN 2093-3827
Author contributions: W.Y.K. and J.-H.K. designed the experimental strategy. J.K.S. and H.R. performed behavioral experiments. J.K.S. and W.Y.K. performed western blot experiments. J.K.S., W.Y.K., and J.-H.K. analyzed the data. J.-H.K. wrote the manuscript. All authors commented on and approved the final manuscript. 
consequent relapse is their ability to confer rewarding effects to the environment associated with them [18-21]. Similar to its role in locomotor sensitization, GSK3 $\beta$ has also been implicated in mediating conditioned rewards formed by associations of psychomotor stimulants and the place that they were given [22-25]. For example, it was shown that the developments of conditioned place preference induced by cocaine and AMPH was prevented by GSK3 $\beta$ inhibitors in mice [22] and rats [24], respectively. However, although the NAcc is known as one of the critical neuronal substrates mediating conditioned behaviors [26,27], it remains undetermined which sub-region of the NAcc GSK $3 \beta$ contributes to mediating conditioned behaviors. Thus, in the present study, we measured the GSK3 $\beta$ phosphorylation levels separately in two sub-regions of the NAcc following the expression of AMPHinduced conditioned locomotor activity. Further, we examined whether conditioned behavior and the accompanying changes in GSK3 $\beta$ phosphorylation recovered following treatment with a GSK3 $\beta$ inhibitor.

\section{METHODS}

\section{Subjects and drugs}

Male Sprague-Dawley rats (6 weeks old) weighing 220-250 g on arrival were obtained from Orient Bio Inc. (Seongnam, Korea). They were housed three per cage in a 12-h light/dark cycle room (lights out at 8:00 pm), and all experiments were conducted during the day. Rats had access to water and food ad libitum at all times. All animal use procedures were conducted according to an approved Institutional Animal Care and Use Committee protocol (approval number: 09-140) of Yonsei University College of Medicine.

D-amphetamine sulfate (United States Pharmacopeia, Rockville, MD, USA) and lithium chloride (Sigma-Aldrich, St. Louis, MO, USA) were dissolved in sterile $0.9 \%$ saline.

\section{Locomotor activity}

Locomotor activity was measured using a bank of 9 activity boxes $(35 \times 25 \times 40 \mathrm{~cm})$ (IWOO Scientific Corporation, Seoul, Korea) made of translucent Plexiglas. Each box was individually housed in a PVC plastic sound attenuating cubicle. The floor of each box consisted of 21 stainless steel rods ( $5 \mathrm{~mm}$ diameter), spaced $1.2 \mathrm{~cm}$ apart, center-to-center. Two infrared light photo beams (Med Associates, St. Albans, VT, USA) were positioned $4.5 \mathrm{~cm}$ above the floor and spaced evenly along the longitudinal axis of the box, to estimate horizontal locomotion. A single locomotor activity was only considered to be legitimate when a rat interrupted two beams consecutively, so as to avoid any possible confounding activities, such as grooming in a spot covering just a single beam.

\section{Design and procedures}

Upon arrival, all rats passed a week-long adaptation period to the new housing environment before conducting any experiments.

In Experiment 1, rats were randomly assigned to three groups: Paired, Unpaired, and Control. During conditioning, rats in these three groups were administered injections in five 2-day blocks. Rats received intraperitoneal injection (IP) of AMPH (1 mg/kg) in locomotor activity boxes on day 1 and saline in their home cages on day 2 (Paired), saline in the activity boxes on day 1 and AMPH in their home cages on day 2 (Unpaired), or saline in both environments (Control). This procedure that we used here has previously been shown to produce conditioned locomotor activity $[27,28]$. On the test, one week after the last conditioning block, all rats were tested for their conditioned locomotor response in the activity boxes for one hour following an IP saline injection.

In Experiment 2, rats were randomly assigned to three groups: Paired, Unpaired, and Control, as defined in Experiment 1. They followed the same procedure as described in Experiment 1 for the development of conditioning. On the test, one week after the last conditioning block, each group of rats were sub-divided into two. Then, they were tested for their conditioned locomotor response in the activity boxes for one hour following an IP saline or lithium chloride $(50 \mathrm{mg} / \mathrm{kg})$ injection.

An entire experimental scheme is depicted (Fig. 1A) and a sum-

\section{A}

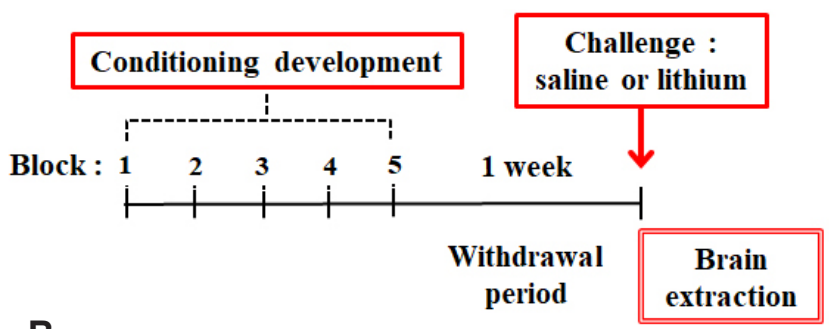

\begin{tabular}{|c|c|c|}
\hline \multirow{2}{*}{ Block } & \multicolumn{2}{|c|}{1 block $=2$ days } \\
\cline { 2 - 3 } & $1^{\text {st }}$ day & $2^{\text {nd }}$ day \\
\hline Injection site & Locobox & Home cage \\
\hline \hline Paired & AMPH & Saline \\
\hline Unpaired & Saline & AMPH \\
\hline Control & Saline & Saline \\
\hline
\end{tabular}

Fig. 1. Experiment outline. (A) An experimental timeline indicates a conditioning development schedule and the point at which challenge and brain extraction were performed. (B) A table summarizes three groups showing where they received AMPH and saline. AMPH, amphetamine. 
mary table, indicating each group's different pairings between drugs and environments, is shown (Fig. 1B).

\section{Brain tissue preparation}

Immediately after completion of behavioral experiments, rats were decapitated by guillotine. Brains were rapidly removed and coronal sections (1.0 mm thick extending 1.60-2.60 mm from bregma) were obtained with an ice-cold brain slicer (Model SA2160; Roboz Surgical Instrument Co., Gaithersburg, MD, USA). The NAcc core (circular punch with $1.0 \mathrm{~mm}$ diameter) and the shell (rectangular shape cut) regions were obtained on an ice-cold plate. Tissues were all immediately frozen on dry ice and stored at $-80^{\circ} \mathrm{C}$. They were prepared bilaterally and pooled for each individual animal's protein isolation.

\section{Western blotting}

Tissues were homogenized in lysis buffer containing $0.32 \mathrm{M}$ sucrose, $2 \mathrm{mM}$ EDTA, 1\% SDS, $10 \mu \mathrm{g} / \mathrm{ml}$ aprotinin, $10 \mu \mathrm{g} / \mathrm{ml}$ leupeptin, $1 \mathrm{mM}$ phenylmethylsulfonyl fluoride, $10 \mathrm{mM}$ sodium fluoride, and $1 \mathrm{mM}$ sodium orthovanadate. The concentration of protein was determined by using Pierce Coomassie Protein Assay Kit (Thermo Scientific Inc., Rockford, IL, USA). Samples were then boiled for $10 \mathrm{~min}$ and subjected to SDS-polyacrylamide gel electrophoresis. Proteins were separated and transferred electrophoretically to nitrocellulose membranes (Bio-Rad, Hercules, CA, USA), which were then blocked with $5 \%$ bovine serum albumin (BSA) in PBS-T buffer (10 mM phosphate-buffered saline plus 0.05 $\%$ Tween-20). Antibodies used to probe the blots were as following: total GSK3 $\beta$ (1:4,000), phosphor-GSK3 $\beta$ (specific to detect phosphorylated GSK3 $\beta$ at serine 9, 1:2,000), purchased from Cell Signaling (Beverly, MA, USA) and diluted in PBS-T with 5\% BSA; $\beta$-actin (1:10,000), purchased from Abcam (Cambridge, UK) and diluted in PBS-T with 5\% skim milk. Two separate gels were used to detect total and phosphorylated proteins, respectively. Primary antibodies were detected with peroxidase-conjugated secondary antibodies, anti-rabbit IgG (1:2,000; KOMA Biotech, Seoul, Korea) diluted in PBS-T with 5\% skim milk, followed by enhanced chemiluminescence reagents (Amersham Biosciences, Arlington Heights, IL, USA) and exposure to X-ray film. Band intensities were quantified based on densitometric values using Fujifilm Science Lab 97 Image Gauge software (version 2.54) (Fujifilm, Tokyo, Japan).

\section{Statistical analyses}

Statistical analyses were performed using Sigma Plot version 12.0 (Systat Software, San Jose, CA, USA). The data were analyzed with one-way or two-way analysis of variance (ANOVA) followed by post-hoc Bonferroni comparisons. Differences between experimental conditions were considered statistically significant at $\mathrm{p}<0.05$.

\section{RESULTS}

\section{Repeated pairing of AMPH to a locomotor activity box produces conditioned locomotor activity}

One week after the last block of the conditioning development schedule, all rats were saline-challenged and locomotor activities were measured (Fig. 2). One-way ANOVA conducted on these data revealed a significant effect of pairing $\left(\mathrm{F}_{2,42}=10.67, \mathrm{p}<\right.$ 0.001). As expected, rats paired with AMPH in the locomotor activity boxes (Paired) showed higher locomotor responses than those in the saline group (Control). Further, the Paired group also exhibited higher locomotor activities when compared to rats ad-

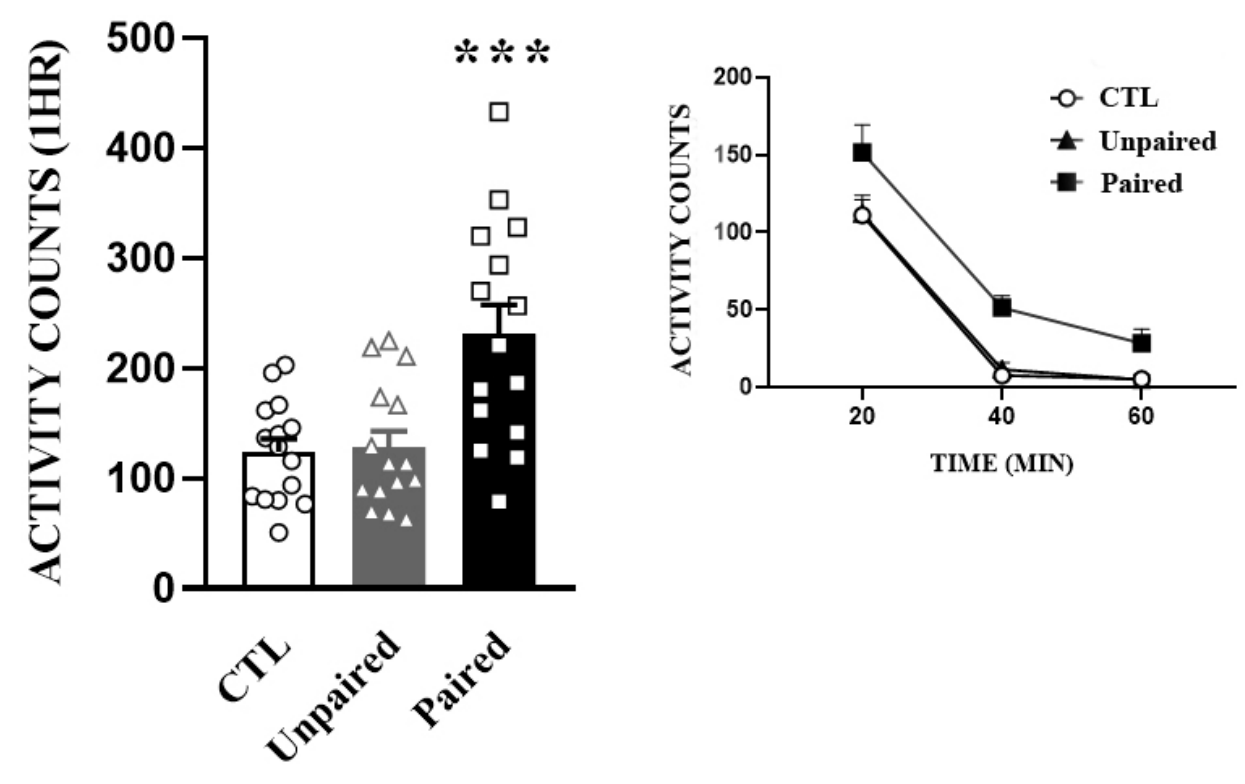

Fig. 2. Paired group shows increased conditioned locomotor activity. All rats were tested following an IP saline injection. Data are shown as group mean + SEM total locomotor activity counts observed during the $1 \mathrm{~h}$ test. Symbols indicate significant differences revealed by post-hoc Bonferroni comparison following one-way ANOVA. ${ }^{* * *} p<0.001$, significantly more counts in the Paired rats relative to those in the Control and Unpaired groups. Time-course data is shown in the inset as group mean + SEM locomotor activity counts at $20 \mathrm{~min}$ intervals. Numbers for each group are 15. $\mathrm{IP}$, intraperitoneal; CTL, control. 
ministered the same amount of AMPH in different environments (Unpaired) ( $\mathrm{p}<0.001$ by post-hoc Bonferroni comparison).

\section{AMPH conditioning decreases GSK3 $\beta$ phosphorylation levels in the NAcc shell}

To test whether the development of AMPH-induced conditioning may regulate GSK3 $\beta$ phosphorylation levels in the NAcc, the ratio of phosphorylated to total GSK3 $\beta$ was examined using Western blotting of samples of two sub-regions of the NAcc obtained $60 \mathrm{~min}$ after saline challenge (Fig. 3). The one-way ANOVA conducted on the data obtained from the core showed no significant effect of pairing $\left(\mathrm{F}_{2,42}=2.09, \mathrm{p}=0.136\right)$. However, the one-way ANOVA conducted on the data obtained from the shell revealed significant effect of pairing $\left(\mathrm{F}_{2,42}=5.28, \mathrm{p}<0.01\right)$. Post-hoc Bonferroni comparisons revealed that the ratio of phosphorylated to total GSK3 $\beta$ in the shell was significantly lower $(\mathrm{p}<$ 0.01 ) in the Paired group than in the Control group.

\section{Lithium chloride inhibits the expression of AMPH- induced conditioned locomotor activity}

In Experiment 2, after the conditioning development, we challenged half of the rats in each group with saline and the other half with lithium chloride, and their locomotor activities were measured (Fig. 4). The two-way ANOVA conducted on these data revealed multiple significant effects of pairing $\left(\mathrm{F}_{2,42}=15.53\right.$, $\mathrm{p}<$ $0.001)$, lithium chloride $\left(\mathrm{F}_{1,42}=14.71, \mathrm{p}<0.001\right)$, and an interaction of pairing and lithium chloride $\left(\mathrm{F}_{2,42}=10.53, \mathrm{p}<0.001\right)$. Again, the Paired group showed higher locomotor responses than the other groups (Control, Unpaired). However, these effects were not observed when challenged with lithium chloride $(\mathrm{p}<0.001$ by post-hoc Bonferroni comparison).
A

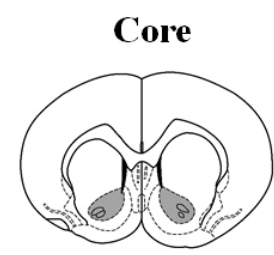

B
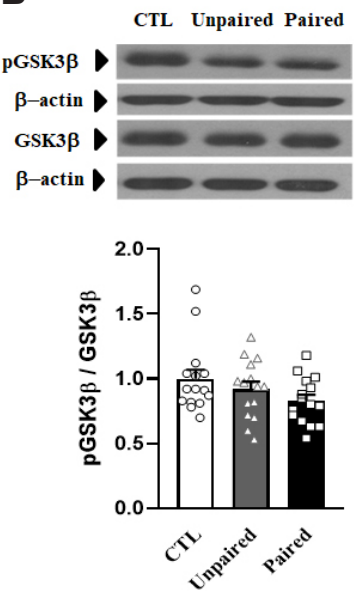

Shell

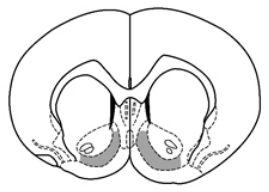

CTL Unpaired Paired
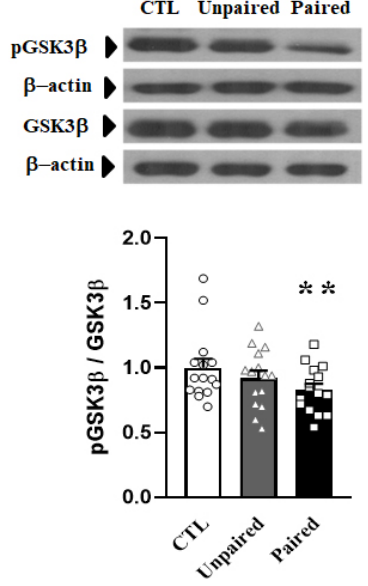

Fig. 3. AMPH conditioning lowers GSK3 $\beta$ phosphorylation levels in the NAcc shell. (A) The core (circle) and the shell (rectangular), two sub-regions of the NAcc, are shown. Punches were prepared bilaterally and pooled for each individual animal's protein isolation. Line drawing is from Paxinos and Watson [39] and depicts the caudal surface of a coronal section (1.0 mm thick) extending $1.70-2.70 \mathrm{~mm}$ from bregma. (B) Representative Western blots are shown. Values for the band intensities were first normalized to $\beta$-actin and then the average values for the ratio of phosphorylated to total proteins in each group were expressed as group mean + SEM. relative to Control group. Symbols indicate significant differences as revealed by post-hoc Bonferroni comparisons following one-way ANOVA. ${ }^{* *} \mathrm{p}<0.01$, significantly different compared to Control group. Numbers for each group are 15. AMPH, amphetamine; GSK3 $\beta$, glycogen synthase kinase $3 \beta$; NAcc, nucleus accumbens.
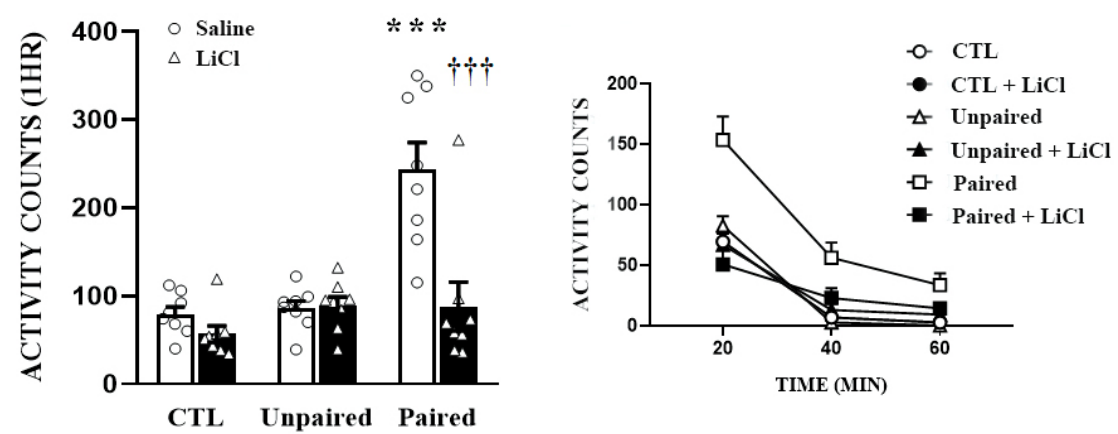

Fig. 4. Lithium chloride inhibits the expression of AMPH-induced conditioned locomotor activity. All rats were tested following an IP saline or lithium chloride $(50 \mathrm{mg} / \mathrm{kg}$ ) injection. Data are shown as group mean + SEM total locomotor activity counts observed during the $1 \mathrm{~h}$ test. Symbols indicate significant differences revealed by post-hoc Bonferroni comparison following two-way ANOVA. *** $<0.001$, significantly more counts in the Paired rats relative to those in the Control and Unpaired groups. ${ }^{t+t} p<0.001$, significantly different from no lithium treated the Paired group. Timecourse data is shown in the inset as group mean + SEM locomotor activity counts at 20 min intervals. Numbers for each group are 8 . AMPH, amphetamine; IP, intraperitoneal; CTL, control; LiCl, lithium chloride. 


\section{Lithium chloride recovers the reduction in GSK3 $\beta$ phosphorylation levels in the NAcc}

Next, we measured the ratio of phosphorylated to total GSK3 $\beta$ levels in the NAcc at 60 min after saline or lithium chloride challenge (Fig. 5). There were no significant effects observed on the data obtained from the core, whereas the two-way ANOVA conducted on data obtained from the shell revealed a significant effect of lithium chloride $\left(\mathrm{F}_{1,42}=6.23, \mathrm{p}<0.02\right)$. Again, the decrease in phosphorylation levels of GSK3 $\beta$ in the shell was only observed in the Paired group ( $\mathrm{p}<0.05$, post-hoc Bonferroni comparison). Interestingly, however, these effects were absent with lithium chloride challenge in the Paired group (Fig. 5). Post-hoc Bonferroni comparisons revealed that rats in the Paired group with lithium chloride challenge showed a significant recovery of GSK3 $\beta$ phosphorylation levels close to Control levels in the shell $(\mathrm{p}<0.01)$.

\section{DISCUSSION}

The present results revealed that the expression of AMPHinduced conditioned locomotor activity accompanied a significant decrease in GSK3 $\beta$ phosphorylation in the NAcc shell. Furthermore, our results revealed that these effects were reversed by lithium chloride, a GSK3 $\beta$ inhibitor.

It was previously shown that GSK3 $\beta$ phosphorylation in the NAcc was decreased when cocaine-associated contextual memory was reactivated [23], while knockdown of GSK3 $\beta$ in the NAcc attenuated the development of cocaine-induced place preference [25]. These results indicate that intact GSK3 $\beta$ activity in the NAcc is necessary for the development and expression of psychomotor stimulants-induced conditioned responses. Consistent with these results, we showed in the present results that GSK3 $\beta$ phosphorylation was lower in the NAcc following the expression of AMPHinduced conditioned locomotor activity. Furthermore, contrary to previous results that did not distinguish the role of GSK3 $\beta$ in the two sub-regions of the NAcc, we found that GSK3 $\beta$ phosphorylation was more significantly reduced in the shell than in the core (Fig. 3). It has been shown in the literature that the NAcc shell plays a more important role in the processing of contextual information than that of the core, and thereby contributes to the context-induced reinstatement of drugs of abuse [29-34]. The increased conditioned locomotor activity toward contextual stimuli associated with drugs of abuse, shown in our present results, can be considered as a manifestation of drug seeking behavior [35]. Accordingly, the finding that a significant decrease in GSK3 $\beta$ phosphorylation in the shell was only observed in the Paired but not in the Unpaired group, which received the same amount of

\section{Core}
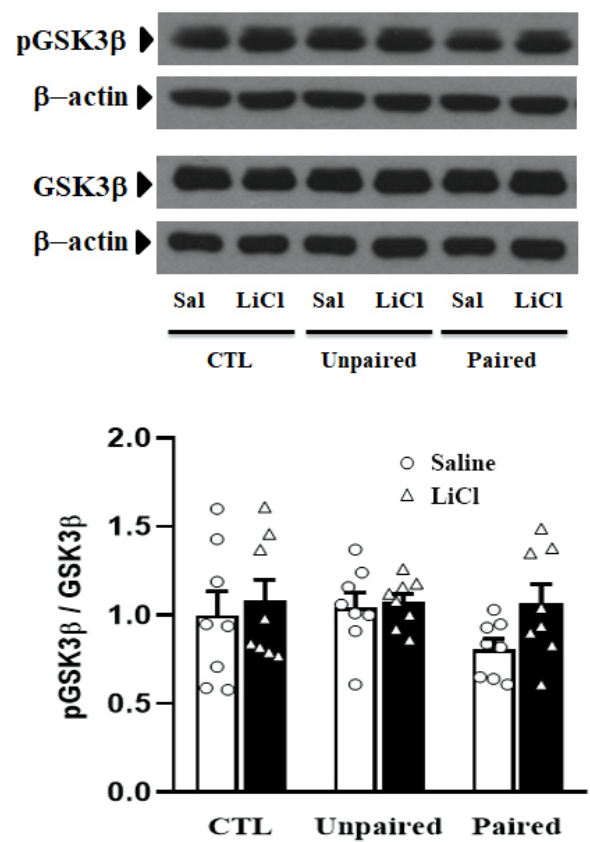

\section{Shell}
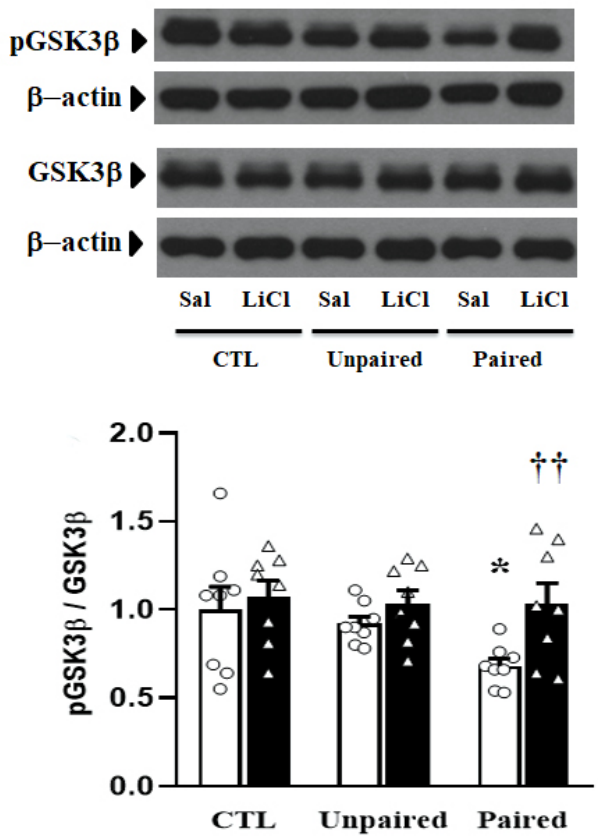

Fig. 5. Lithium chloride recovers a reduction in GSK3 $\beta$ phosphorylation levels in the NAcc shell. Representative Western blots are shown. Values for the band intensities were first normalized to $\beta$-actin and then the average values for the ratio of phosphorylated to total proteins in each group were expressed as group mean + SEM relative to saline challenged Control group. Symbols indicate significant differences as revealed by post-hoc Bonferroni comparisons following two-way ANOVA. ${ }^{*} p<0.05$, significantly different compared to Control group. ${ }^{t \dagger} p<0.01$, significantly different from no lithium chloride treated the Paired group. Lithium chloride treatment also recovered the lowered GSK3 $\beta$ phosphorylation levels in the Paired

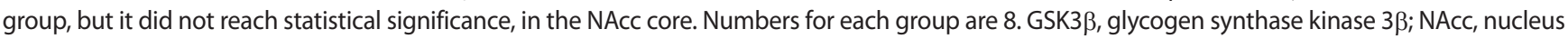
accumbens; CTL, control; LiCl, lithium chloride. 
AMPH in a different place, imply that they may reflect a specific role of GSK3 $\beta$ signaling in mediating conditioning effect of AM$\mathrm{PH}$-associated environmental stimuli.

It was previously shown that the development of conditioned place preference induced by cocaine or AMPH was prevented by either systemic or intra-accumbal injection of a GSK3 $\beta$ inhibitor [22-24]. Consistent with these results, we showed that lithium chloride, a GSK $3 \beta$ inhibitor, completely abolished the expression of conditioned locomotor activity (Fig. 4). In addition, we also demonstrated that the decrease in GSK3 $\beta$ phosphorylation in a drug-associated conditioning model was normalized back to control level by lithium chloride treatment following behavioral recovery (Fig. 5). As lithium chloride is known to have the ability to increase the phosphorylation levels of Akt, an up-stream effector of GSK3 $\beta$, and thereby its phosphorylation levels [36,37], our present findings suggest that GSK3 $\beta$ signaling in the NAcc shell may be under the general regulation of the well-known phosphatidylinositol 3-kinase (PI3 kinase) and Akt signaling pathways. Looking into downstream components, it is not yet known what signaling molecules are involved in the expression of AMPHinduced conditioned locomotor activity. Interestingly, in rats associated with AMPH, dendritic spine density was increased in the shell only in Paired rat [35]. Further, it was recently shown that ezrin-radixin-moesin (ERM) proteins, a group of proteins which play a role in cell-shape determination and spine maturation, are under the regulation of Akt-GSK3 $\beta$ signaling pathways [38], suggesting that there is a possibility for GSK3 $\beta$ to become involved in spine formation. Thus, it will be interesting to examine in the future how GSK3 $\beta$ is involved in these process to eventually contribute to the expression of AMPH-induced conditioned locomotion.

\section{FUNDING}

This work was supported by a grant from The Myung-Sun Kim Memorial Foundation.

\section{CONFLICTS OF INTEREST}

The authors declare no conflicts of interest.

\section{REFERENCES}

1. Robbins TW, Cador M, Taylor JR, Everitt BJ. Limbic-striatal interactions in reward-related processes. Neurosci Biobehav Rev. 1989; 13:155-162.

2. Kalivas PW, Stewart J. Dopamine transmission in the initiation and expression of drug- and stress-induced sensitization of motor activity. Brain Res Brain Res Rev. 1991;16:223-244.
3. Hyman SE. Addiction to cocaine and amphetamine. Neuron. 1996;16:901-904.

4. Goto Y, Grace AA. Limbic and cortical information processing in the nucleus accumbens. Trends Neurosci. 2008;31:552-558.

5. Beaulieu JM, Gainetdinov RR, Caron MG. The Akt-GSK-3 signaling cascade in the actions of dopamine. Trends Pharmacol Sci. 2007;28:166-172.

6. Beaulieu JM, Gainetdinov RR, Caron MG. Akt/GSK3 signaling in the action of psychotropic drugs. Annu Rev Pharmacol Toxicol. 2009;49:327-347.

7. Leroy K, Brion JP. Developmental expression and localization of glycogen synthase kinase-3beta in rat brain. J Chem Neuroanat. 1999;16:279-293.

8. Dajani R, Fraser E, Roe SM, Young N, Good V, Dale TC, Pearl LH. Crystal structure of glycogen synthase kinase 3 beta: structural basis for phosphate-primed substrate specificity and autoinhibition. Cell. 2001;105:721-732.

9. Frame S, Cohen P, Biondi RM. A common phosphate binding site explains the unique substrate specificity of GSK3 and its inactivation by phosphorylation. Mol Cell. 2001;7:1321-1327.

10. Miller JS, Tallarida RJ, Unterwald EM. Cocaine-induced hyperactivity and sensitization are dependent on GSK3. Neuropharmacology. 2009;56:1116-1123.

11. Xu CM, Wang J, Wu P, Zhu WL, Li QQ, Xue YX, Zhai HF, Shi J, Lu L. Glycogen synthase kinase 3beta in the nucleus accumbens core mediates cocaine-induced behavioral sensitization. J Neurochem. 2009;111:1357-1368.

12. Xu CM, Wang J, Wu P, Xue YX, Zhu WL, Li QQ, Zhai HF, Shi J, Lu L. Glycogen synthase kinase $3 \beta$ in the nucleus accumbens core is critical for methamphetamine-induced behavioral sensitization. $J$ Neurochem. 2011;118:126-139.

13. Enman NM, Unterwald EM. Inhibition of GSK3 attenuates amphetamine-induced hyperactivity and sensitization in the mouse. Behav Brain Res. 2012;231:217-225.

14. Kim WY, Jang JK, Lee JW, Jang H, Kim JH. Decrease of GSK3 $\beta$ phosphorylation in the rat nucleus accumbens core enhances cocaine-induced hyper-locomotor activity. J Neurochem. 2013;125: 642-648.

15. Jongen-Rêlo AL, Voorn P, Groenewegen HJ. Immunohistochemical characterization of the shell and core territories of the nucleus accumbens in the rat. Eur J Neurosci. 1994;6:1255-1264.

16. Zahm DS. An integrative neuroanatomical perspective on some subcortical substrates of adaptive responding with emphasis on the nucleus accumbens. Neurosci Biobehav Rev. 2000;24:85-105.

17. Meredith GE, Baldo BA, Andrezjewski ME, Kelley AE. The structural basis for mapping behavior onto the ventral striatum and its subdivisions. Brain Struct Funct. 2008;213:17-27.

18. Stewart J, Vezina P. Conditioning and behavioral sensitization. In: Kalivas PW, Barnes CD, editors. Sensitization in the nervous system. Caldwell: Telford Press; 1988. p.207-224.

19. O'Brien CP, Childress AR, McLellan AT, Ehrman R. Classical conditioning in drug-dependent humans. Ann N Y Acad Sci. 1992; 654:400-415.

20. Domjan M. Pavlovian conditioning: a functional perspective. Annu Rev Psychol. 2005;56:179-206.

21. Tzschentke TM. Measuring reward with the conditioned place preference (CPP) paradigm: update of the last decade. Addict Biol. 
2007;12:227-462.

22. Miller JS, Barr JL, Harper LJ, Poole RL, Gould TJ, Unterwald EM. The GSK3 signaling pathway is activated by cocaine and is critical for cocaine conditioned reward in mice. PLoS One. 2014;9:e88026.

23. Shi X, Miller JS, Harper LJ, Poole RL, Gould TJ, Unterwald EM. Reactivation of cocaine reward memory engages the Akt/GSK3/ mTOR signaling pathway and can be disrupted by GSK3 inhibition. Psychopharmacology (Berl). 2014;231:3109-3118.

24. Wickens RH, Quartarone SE, Beninger RJ. Inhibition of glycogen synthase kinase-3 by SB 216763 affects acquisition at lower doses than expression of amphetamine-conditioned place preference in rats. Behav Pharmacol. 2017;28:262-271.

25. Shi X, Barr JL, von Weltin E, Wolsh C, Unterwald EM. Differential roles of accumbal GSK3 $\beta$ in cocaine versus morphine-induced place preference, U50,488H-induced place aversion, and object memory. $J$ Pharmacol Exp Ther. 2019;371:339-347.

26. Franklin TR, Druhan JP. Involvement of the nucleus accumbens and medial prefrontal cortex in the expression of conditioned hyperactivity to a cocaine-associated environment in rats. Neuropsychopharmacology. 2000;23:633-644.

27. Kim WY, Vezina P, Kim JH. Blockade of group II, but not group I, mGluRs in the rat nucleus accumbens inhibits the expression of conditioned hyperactivity in an amphetamine-associated environment. Behav Brain Res. 2008;191:62-66.

28. Yoon HS, Kim WY, Kim JH. Microinjection of CART peptide 55102 into the nucleus accumbens core inhibits the expression of conditioned hyperactivity in a cocaine-associated environment. Behav Brain Res. 2010;207:169-173.

29. Bossert JM, Poles GC, Wihbey KA, Koya E, Shaham Y. Differential effects of blockade of dopamine D1-family receptors in nucleus accumbens core or shell on reinstatement of heroin seeking induced by contextual and discrete cues. J Neurosci. 2007;27:12655-12663.
30. Fuchs RA, Ramirez DR, Bell GH. Nucleus accumbens shell and core involvement in drug context-induced reinstatement of cocaine seeking in rats. Psychopharmacology (Berl). 2008;200:545-556.

31. Chaudhri N, Sahuque LL, Schairer WW, Janak PH. Separable roles of the nucleus accumbens core and shell in context- and cueinduced alcohol-seeking. Neuropsychopharmacology. 2010;35:783791.

32. Xie X, Lasseter HC, Ramirez DR, Ponds KL, Wells AM, Fuchs RA. Subregion-specific role of glutamate receptors in the nucleus accumbens on drug context-induced reinstatement of cocaine-seeking behavior in rats. Addict Biol. 2012;17:287-299.

33. Cruz FC, Babin KR, Leao RM, Goldart EM, Bossert JM, Shaham Y, Hope BT. Role of nucleus accumbens shell neuronal ensembles in context-induced reinstatement of cocaine-seeking. J Neurosci. 2014;34:7437-7446.

34. Singer BF, Forneris J, Vezina P. Inhibiting cyclin-dependent kinase 5 in the nucleus accumbens enhances the expression of amphetamineinduced locomotor conditioning. Behav Brain Res. 2014;275:96-100.

35. Singer BF, Bubula N, Li D, Przybycien-Szymanska MM, Bindokas VP, Vezina P. Drug-paired contextual stimuli increase dendritic spine dynamics in select nucleus accumbens neurons. Neuropsychopharmacology. 2016;41:2178-2187.

36. Beaulieu JM, Caron MG. Looking at lithium: molecular moods and complex behaviour. Mol Interv. 2008;8:230-241.

37. Beaulieu JM, Del'guidice T, Sotnikova TD, Lemasson M, Gainetdinov RR. Beyond cAMP: the regulation of Akt and GSK3 by dopamine receptors. Front Mol Neurosci. 2011;4:38.

38. Kim WY, Cai WT, Jang JK, Kim JH. Ezrin-radixin-moesin proteins are regulated by Akt-GSK3 $\beta$ signaling in the rat nucleus accumbens core. Korean J Physiol Pharmacol. 2020;24:121-126.

39. Paxinos G, Watson C. The rat brain in stereotaxic coordinates. Boston: Elsevier Academic Press; 2004. 